\title{
Exploring the Elements of Integrity in Peer Assessment
}

\author{
Noor Atikah Zainal Abidin 1,*, Alias Masek $^{2}$, and Nur Sofurah Mohd Faiz ${ }^{3}$, and Shafizza Sahdan ${ }^{4}$ \\ 1,2, 3\& 4 Faculty of Technical and Vocational Education, Universiti Tun Hussein Onn Malaysia, 86330 Batu Pahat, Johor, \\ Malaysia.
}

\begin{abstract}
Peer assessment is one of the best methods to evaluate group work of students. However, integrity of students as assessors is still questionable. Hence, the purpose of this study is to explore the elements of students' integrity in carrying peer assessment. The qualitative approach using the document analysis and interviews is used to explore the elements of integrity in peer assessment. In an effort to increase the acceptance of this evaluation approach, the results show that the student's integrity in conducting peer assessment consists of three elements, which are self-integrity, integrity in social interaction and work commitment.
\end{abstract}

\section{Introduction}

Periodic assessments carried out during the teaching and learning process will reveal students' progress over time. Tracking students' academic performance on a regular basis provides feedback to the teachers about the problems faced by students [1]. Do students have difficulties in learning and mastering the knowledge and skills that have been taught? If the answer is in the affirmative, the teachers will investigate the root cause. The teachers can then use the information obtained from the investigation to change their teaching approach or provide special training; this will help students overcome the problems they face. Without this special assistance, students' problems will remain unsolved, and they will continue to fall behind in learning. Peer assessment is one of the alternatives to monitor students' learning progress, through which the teachers can carry out corrective measures to improve students' performance.

According to [2], peer assessment refers to a process in which students think critically and suggest the best grade for their friends. In peer assessment, students use a checklist or rubric, which helps them in various aspects of learning, whether they are assessed or assess others. Sharing the criteria of assessment empowers students to evaluate their own performance and their friends. The ability to work effectively with others in a group is one of the critical ways to achieve learning success. [3] states that peer assessment is a process in which students assess the quality of work of their fellow students and provide each other with feedback.

According to [1], peer assessment is a rule for students to consider and determine the extent, value, or quality of products or the performance of other students. Students provide marks for the work or show their friends the standard of learning using pre-defined criteria $[4,5]$. In order for students to determine the fair value of marks, the lecturer must create an environment that gives them the opportunity to participate [5]. Previous studies often discuss issues related to the implementation of peer assessment. This is due to the social influences that may affect the reliability and validity of peer assessment. The relationship between partners is the main factor that affects the reliability and validity of peer assessment and it includes these aspects: the bonds of friendship, enmity, individual popularity, negative perceptions and discrimination between genders [1].

Therefore, the aim of this study is to explore the elements of student's integrity in conducting peer assessment and to raise the acceptance level of this assessment approach among them.

\section{Methodology}

This study was conducted using the qualitative approach to explore the integrity of students in carrying out peer assessment. Two methods were used to obtain the results of the study: analysing documents and conducting interviews. Documents from several sources were analysed, including previous studies, model of integrity and assessment policy, principles and guidelines. The document analyses were carried out on scientific papers published from the years 1996 to 2017. Search engines were utilised to gather papers from various sources, including Google Scholar and selected journal databases relevant to assessment, i.e. ELT journal, journal computers in human behaviour, radiography journal, assessment in education, assessment and evaluation in education, and Malaysian online journal of educational technology. These are the search terms deployed for data collection: peer assessment, bias of assessment, factor affect peer assessment process, marking influence by demography, gender bias in peer assessment, friendship bias in peer assessment, policy marking in assessment,

\footnotetext{
* Corresponding author: ika.unimas@gmail.com/hb14079@siswa.uthm.edu.my
} 
model of integrity, conceptual of integrity and disadvantage of peer assessment.

This research study involved six experts in the fields of Professional Education and Technical and Vocational Education (TVET); they are familiar with and experienced in teaching and learning, especially in matters related to peer assessment. Interviews were conducted to collect these data: information of peer assessment, bias of assessment, factors affecting peer assessment process, marking influence by demography, gender bias in peer assessment, and friendship bias in peer assessment. The data were then analysed along thematic lines. The thematic analyses were conducted in order to organise the data collected into clear groups of topical information needed to answer the research questions.

The qualitative data analysis was conducted based on the six steps recommended by [6]. These are the six steps of conducting thematic analysis:

(i) A researcher needs to be familiar with the data; he or she should know the data that are important. The researcher needs to read the documents carefully and take note of the initial ideas.

(ii) The researcher generates the initial codes based on the data or transcripts. He or she should collate the data related to each code.

(iii) The researcher searches the themes of the data and classifies them into groups.

(iv) The researcher needs to review the data and ensure the suitability of the themes.

(v) The researcher must define and name themes that interpret the groups of data. He or she will then generate a definition for each theme.

(vi) The researcher writes the report based on the findings.

\section{Findings}

A total of three main themes have emerged from the document analysis and thematic analysis of the interview data, representing the group elements of students' integrity in peer assessment discussed in detail as follows:

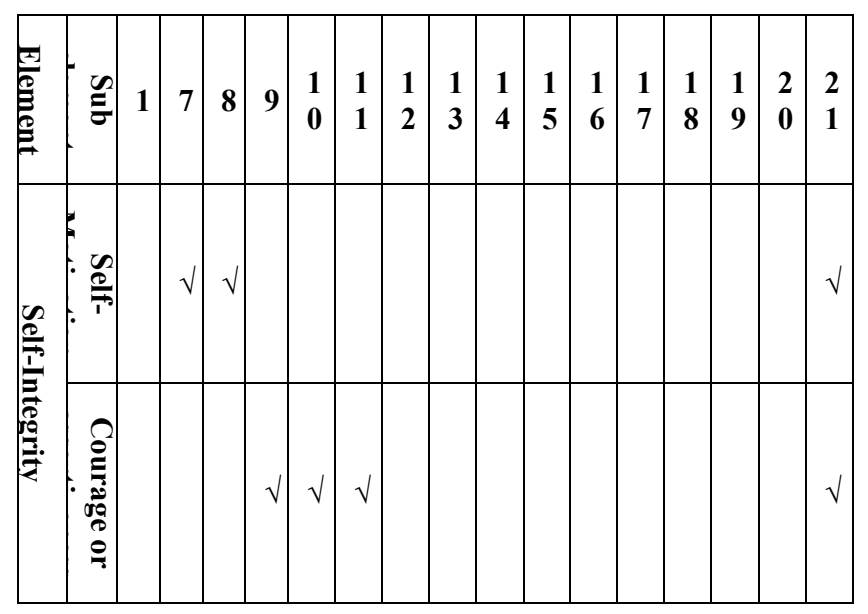

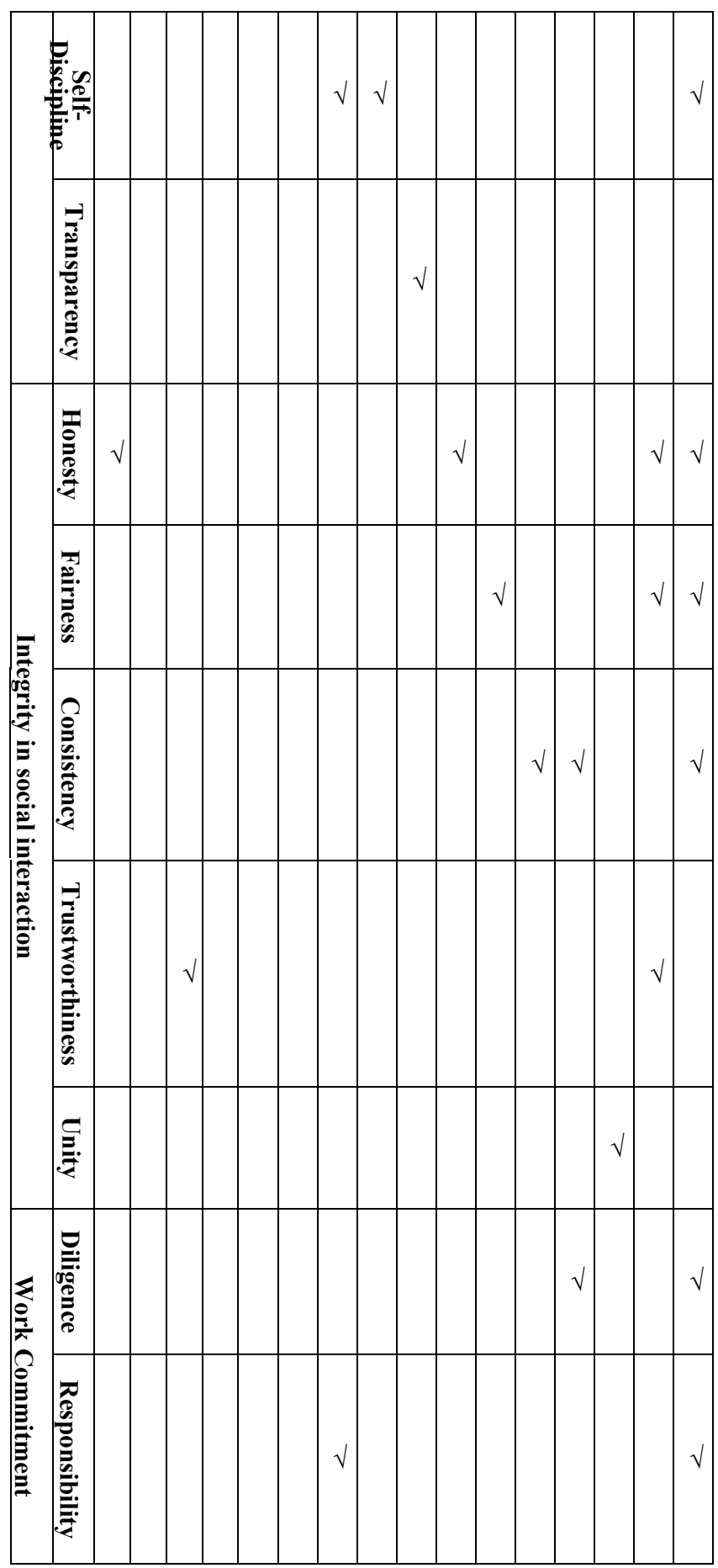

\subsection{Self-Integrity}

Self-integrity is one of the elements of a student's integrity during peer assessment. Self-integrity is defined as something that happens inside an individual or in his/her mind. In peer assessment, self-integrity of a student influences the integrity of conducting the assessments that have several sub-elements. There are three sub-elements of self-integrity, namely selfmotivation, courage or assertiveness, and self-discipline. 


\subsubsection{Self- Motivation}

Self-motivation is defined as an inner drive of a person to achieve the goals set. Students who have selfmotivation are more likely to motivate themselves to evaluate the work of others, and at the same time, rated by other students; peer assessment based on such positive attitudes and practices will produce results of high validity and reliability. Helpful and patient teachers are a good example who will motivate students to become effective evaluators. However, there are students who are not self-motivated to conduct an assessment. When students are not self-motivated, they feel peer assessment is a burden to them. Hence, self-motivation plays a crucial role for students to conduct peer assessments.

\section{“..He/she does not have knowledge..” (Participant 1)}

“..What I am expecting from students...maybe they cannot conduct a good assessment due to the fact that he/she does not have knowledge, commitment, or he/she does not trust, dishonest among their friends.."

(Participant 2)

“..Peer assessment can encourage students to exchange opinions and accept others' opinions... indirectly it can increase students' motivation in groups, to give full commitment in group activities.." (Participant 3 )

"..At the same time, the absence of transparency causes a student who is assessed with no transparency to have less motivation in learning. This is because they have done as well as possible, but peer assessments have destroyed their brilliant performance.." (Participant 4)

"..I think the best thing is to see the view from others, others' angle, other than from the lecturer's view... assessment toward, from the lecturer's view, maybe from the soft skills that students assess themselves, through peers... how they conduct their field work,

communication with client... with the absence of lecturer, students in that group know he/she is good in communication, they can rank them.." (Participant 5)

\subsubsection{Courage or Assertiveness}

Courage or assertiveness is the quality of a person who acts upon and maintains the principles they believed in. Past studies found that some students are stressed out in conducting peer assessment. This proves that the students do not have the courage to make a decision in giving marks to their friends. Students think that they are not qualified to give marks to their friends as their knowledge is at about the same level as their friends. Courage within students is needed to overcome the integrity issues in peer assessment.

"..we want to train students to become brave, confident in assessing their friends.." (Participant 2)
“..A positive learning environment, for example, students should be brave and firmly give an opinion during peer assessment.." (Participant 3)

"..Other than that, students who assess other friends should be credible, not easily influenced and reliable. In this case, when they assess, they must strongly stand on their judgment and cannot be influenced by others.." (Participant 4)

\subsubsection{Self-Discipline}

Self-discipline refers to the quality of someone who can follow the guidelines given or regulations that have been set. Students who have a high degree of self-discipline are able to follow the rules and guidelines of evaluation while conducting peer assessment. Results from the thematic analysis found that students need to evaluate the work of their colleagues using guidelines and the criteria that have been set, so that the validity and reliability of an assessment are unquestionable. When students follow the guidelines, they will focus on the job of assessment rather than other things such as their personal problems.

"..If students want to evaluate their friend, he/she will not take it seriously.." (Participant 2)

“..Evaluating according to rubric that had been provided, discipline should be taken into consideration in order to avoid distraction on integrity.." (Participant 3)

\subsubsection{Transparency}

Transparency means students must be honest with the evaluators when a peer assessment is being conducted. Transparency is inward quality or honest behaviour of the students. It is an important ingredient in creating integrity of students. When students have a good trait of transparency in conducting an assessment, they will exhibit the same behaviour in other matters.

“..If he/she likes, he/she will give high marks to that person. But if we ask a female student, for sure she will give high marks.." (Participant 1)

“..When a friend assesses other peers' cooking styles, he/she should judge based on the rubric and give criticism for improvement, and praise if it is brilliant, so that this marking is transparent ... In this case, a student must be open and accept the views and criticism of others to avoid mistakes, improve any weaknesses.. "(Participant 4)

\subsection{Integrity in social interaction}

Social interaction is the act of an individual associated with or has contact with other individuals. Integrity of social interactions occurs outside of student's life. Integrity of social interactions can be related to external factors that contribute to a student's criteria. There are 
five sub-elements under the integrity of social interactions: honesty, fairness, consistency, trustworthiness and unity.

\subsubsection{Honesty}

Honesty refers to intention and ability to do something in a transparent manner, be open to yourself and others. In conducting an honest appraisal, a student rates transparently and openly without being influenced by feelings of bias. Analyses found that students tend to give high marks because of their compassion, relationship with the student being assessed and the status of that student. Honesty is hard to measure, but when people around behave in an open and transparent manner, they create an environment of honesty; hence, it is possible to train and develop a good and honest student. People around with negative attitudes can influence the honesty of students as they tend to listen to their friends' opinions and do not care about the integrity when they assume the role of an assessor.

".. We know that in the class he is a friend of that person, so, we need to ask him to evaluate others.... From the teacher's aspect, this student may not be able to conduct the assessment well because he does not have knowledge, is not committed or because he is not trustworthy, and is dishonest with her friends.." (Participant 2)

"..Students' perceptions are varied; hence, their implications will expect something different, will ultimately lead to unequal and illogical scoring systems ... There are those who are good friends and the impact is high marks and vice versa .." (Participant 4)

"..Being dishonest when they are assessors in peer assessment...depicts low performance but high scores .." (Participant 6)

\subsubsection{Fairness}

Justice is a quality of someone who can make fair decisions, without bias and prejudice, especially when the decisions will affect the welfare of other people. A peer assessment will be useful when the process is carried out in a fair and equitable manner. Students who are fair in the assessment will produce high-quality assessment grades that reflect the real performance of those being evaluated. The study findings reveal that the grades of a fair and equitable assessment conducted by a friend are not different from the scores assessed by the teacher. The practice of fairness among students could create an environment that will generate good and quality marks in peer assessment; the students know how to be objective and handle the process of giving marks with a cool head. Sometimes, it is hard for students to be as fair as they can; teachers, as the facilitators, can play their roles by reminding and encouraging students to maintain the stance of impartiality when carrying out peer assessments.
"..Students must be transparent to evaluate a friend fairly...do it fairly, without being influenced by the feeling of giving more scores to certain individuals.." (Participant 4)

\subsubsection{Consistency}

Consistency refers to the quality of someone who organises something repeatedly based on the same principles. Students must be able to carry out evaluations with integrity consistently without being affected by other factors. The findings of the study show that when students assume the role of an assessor, they should adhere to the criteria specified strictly in evaluating the work of their friends; the marks given will then be fair and unbiased. Consistent marks given during peer assessments are of paramount importance; such practice gives the assurance, both to students and teachers, that peer assessment is a workable and reliable method of evaluation. If students give marks according to their moods or swayed by their assignment burden, the marks given will not be valid and cannot be used as an instrument to gauge the performance of a student.

".. What the teacher expects is that, the student may not be able to do well because he has no knowledge, no commitment or because he is not trustworthy, dishonest among his friends.." (Participant 2)

\section{"..Their assessment must be based on a rubric set by the teacher rather than on emotional pursuing.."} (Participant 4)

"... if it's an individual, it's possible to have integrity, for example we are helping each other ... in a group of 5 students ... we ask each of the students to assess their friends ... but if it is in the group, they need to discuss first ... for example in a group of 5 students, the first group will present and the score for the first group will be discussed among the 4 groups... "(Participant 5)

\subsubsection{Trustworthiness}

Trust is the feeling of confidence in someone that he or she has the ability to do something. Students believe that the results given by their friends as peer assessors are valid and reliable. The data from thematic analysis found that students trust their friends who play the role of evaluators while conducting peer assessment. However, there are researchers who said that students are worried with the marks given by their friends. This is because students think that their friends cannot be trusted and it is hard even to trust themselves. This normally happens when students themselves do not have the confidence, and they also have no confidence in their friends; hence, in their mind, no one around them is trustworthy. Good assessors should exhibit the quality of trustworthiness during peer assessment, so that the marks given are valid and can be used as positive feedback to improve their friends' performance in the future. 
"..Incurred losses in assessment due to a miscalculation, resulting in a student getting low marks, who was supposed to get a high score.." (Participant 4)

\subsubsection{Unity}

Unity refers to the consensus of fellow students in the class in giving assessment feedback without being influenced by any factors. Unity of students in the class is important as the value and quality of scores in peer assessment depend on them. When all the students are united and cooperate with one another in conducting peer assessment, the process will be smoother and acceptable to all people.

\section{"..They will know if their friends do the work well, as they work in a group.." (Participant 2)}

"..Students are educated with collaborative skills, which will create unity among students. If the students are united, there will be no student with no integrity... If one person does something wrong, all the group members will be involved later.. "(Participant 3)

\subsection{Work Commitment}

Work commitment refers to the strong belief of students to do a job well while conducting peer assessment as an evaluator. A student needs to view work commitment as a serious matter and incorporate it into their lifestyle, as this can train them to be more responsible in the future. Work commitments are important in the process of peer assessment; each score given by a committed evaluator is valid and can be used to measure students' performance. Students who do not have work commitment will think that peer assessment is just another normal evaluation exercise; they do not take the assessment seriously and therefore the results are not useful. The sub-elements of work commitment are commitment, diligence, responsibility and ethics.

Commitment is the quality of someone who has the passion in carrying out an activity or assignment. Students who have a high level of integrity are committed to do their assignments. Previous studies found that students are comfortable when they are evaluated by their friends, and this method can be used to improve their communication skills [1]. Students must be encouraged to embrace commitment when they are in the school; when they are working in the future, the quality of commitment will show up in the workplace, leading to excellent work performance. A student who does not have commitment in conducting a peer assessment will not do a good job and produce results that are not useful to anyone.

\subsubsection{Diligence}

Diligence refers to the quality of someone who is hardworking in carrying out the tasks given and does something earnestly. A diligent person will endeavour to carry out a task to the best of his ability. Peer assessments are an on going process that needs an appraiser who can diligently assess and give marks to the work of a peer, commensurate with the quality.

"..Not focus. He/she does not have the commitment, does not know what to assess ..... but to me if the administrator observes, it will be much easier because we've prepared. We have tried. But peer assessment may not be carried out .. "(Participant 1)

"..They compete, which group will be able to collect the most stars, and they will get a prize." In conclusion, they would get the star for the sake of what I have commented.."(Participant 2)

\subsubsection{Responsibility}

Responsibility in this study is the quality of someone who is willing to be accountable for a duty given in order to achieve the goals and objectives set. Responsible evaluators are students who accept the job of peer assessments in accordance with the procedures laid down by the lecturer without being influenced by other factors. According to the searched results of research literature, responsibility is an element of the student integrity, and students are aware of the job responsibilities of an assessor when they conduct a peer assessment.

".. first is that students should know that they should be sincere to take up the responsibility as someone who needs to assess other friends...Sometimes, students assume the task of evaluating, which is the duty of the teacher, and they think they do not need to be involved with the assessment task .." (Participant 4)

\subsubsection{Ethics}

The element of ethics refers to the quality of a student who sticks to good moral principles when conducting a peer assessment. Ethical students can distinguish between good and bad actions while conducting the assessment. With the practice of good ethics among students, the running of the assessment process will be smooth, which in turn will produce useful feedback for the assessors and their peers. Ethics are an important part in the social development of students' life; when students do not have any ethics, they will live their lives carelessly without rules and principles. This will affect the employability of students in the future.

"..Students must understand what needs to be evaluated and what the values are according of what the lecturer wants him to value... Do not evaluate just like that..." (Participant 3)

\section{"..If you have some kind of secrecy, it is about the} marks.." (Participant 5) 


\section{Discussions}

In an effort to increase the acceptance of peer assessment, three elements of student's integrity need to be considered in conducting peer assessment, which are self-integrity, integrity in social interaction and workoriented commitment. The element of self-integrity has four sub-elements, and they are self-motivation, courage or assertiveness, self-discipline and transparency. The statement is supported by a previous study that states students are not prepared to conduct peer assessment [7]. In addition, they are worried that their opinions expressed during peer assessment might be used by other students, and some students might not be serious in conducting peer assessment [8]. Some researchers found that there is a problem in controlling the cost of conducting peer assessment, and there is a lack of trust in peer assessment [9]. This is due to the reason that students might give higher marks to their teammates $[9,10]$. There are several factors that can influence the self-discipline of students such as nature of a subject, number of products or performance assessed, gender difference, racial and cultural background $[12,13]$. From the findings of a previous study, the gender-based differences may influence the transparency of a student whilst doing the assessment [14].

Integrity in social interaction has five subelements: honesty, fairness, consistency, trustworthiness and unity. Honesty of a student can be influenced by friendship, reference, purpose (development or grading), feedback (effects of negative feedback on future performance), collusive behaviours (lack of differentiation) bias, enmity or other power processes and the popularity of individuals $[15,1]$. Hence, friendship bias does not affect the outcome of peer assessment as marks given by teachers, peers and nonpeers are the same and according to the quality and performance [16]. In addition, students do not understand the criteria of peer assessment, which will not lead to quality assessment [17]. Teachers should provide some guidelines by giving practical examples so that students can use the right procedure to conduct peer assessments [18]. In peer assessment, students think that they should be assessed by higher-level students in order to receive feedback from persons who are more experienced [8]. In the same way, marks from several assessors should be taken into consideration because the average of the scores could neutralise the effects of bias on a student's marks [19].

The element of work commitment has three subelements: diligence, responsibility and ethics. Training and briefings on evaluation criteria should be conducted to assist students in understanding the role of the assessor and the process of assessing [18]. Past studies do not discuss the sub-elements of responsibility and ethics in peer assessment. However, responsibility [21] and ethics are important sub-elements and should be emphasised in assessment policies and models. This effort will help to improve the quality of peer assessment.
These elements and sub-elements measure the integrity of students. Each element or sub-element is supported by evidence and therefore is suitable to measure the integrity in peer assessment. Each element or sub-element has been validated by a few experts, and hence all the elements and sub-elements are suitable instruments with the right construct. Each sub-element has been improved based on the interviews of experts in Profession Education and Technical and Vocational Education. The sub-element of ethics has been improved and added. No specific framework of integrity in peer assessment has been developed in previous studies. Hence, the framework of student integrity in conducting peer assessment has been developed in this study. New elements as contained in Figure 1 must be taken into account in order to measure the overall integrity of students in peer assessment.

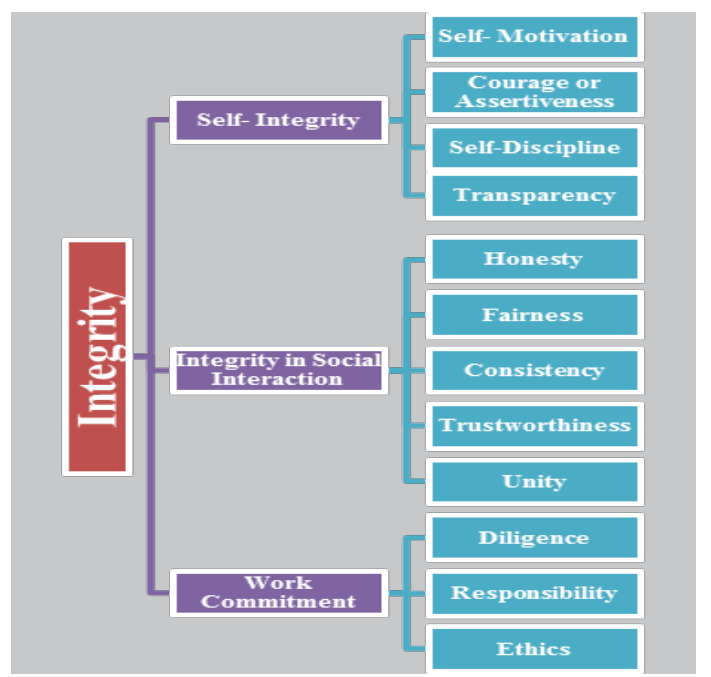

Fig. 1. Elements of student integrity

\section{Conclusion}

In conclusion, students need to have integrity in order to conduct peer assessments of high validity and reliability [22]. Highly valid and reliable peer assessments are a crucial factor that will convince all lecturers and education experts to accept and implement this alternative evaluation method. A good student who does his or her job with integrity will perform well in the workplace in the future. A student who has a high level of integrity in their learning process will attain better results; they are able to pursue self-regulated learning more consistently and achieve excellent academic performance [23]. Quality students are good assessors and will do a good job during peer assessments [22]. Integrity of students is important and indeed necessary to improve the validity of peer assessments. When peer assessment is perceived as a valid and reliable method of evaluation, many people, particularly those in the field of education will implement this alternative assessment tool in their teaching process. There is no doubt about it; peer assessment can be an avenue to churn out more skilled students in the future. The personality and reputation of a student can be a factor affecting the outcome of a peer 
assessment [23]. Students who have experienced the benefits of peer assessments think that this is a good practice in the learning process, but some students think negatively of this assessment method [24]. This will adversely affect the integrity of elementary students in the process of peer evaluation. Thus, the elements of the student integrity should be explored further to increase the validity of this assessment, and to motivate teachers to use the peer assessment as a method of teaching and learning. It is suggested that future researchers look into the development of a model for the study of the relationship between the elements of integrity. Lecturers can examine the integrity levels of students while conducting peer assessments.

The author would like to thank the Ministry of Higher Education (Mybrain 15) and Universiti Tun Hussein Onn Malaysia (UTHM) for the funding of this research project.

\section{References}

1. K. Topping. Peer Assessment. Theory Into Practice. 48 (1), 20 - 27 (2009).

2. A.S. Roberts, S.I. Benrimoj, T.F. Chen, K.A. Williams, P. Aslani. Implementing cognitive services in community pharmacy: A review of facilitators used in practice change. International Journal of Pharmacy Practice, 14, 163 - 170 (2006)

3. V.D.I. Berg. Peer assessment in universiti teaching : Evaluating seven course designs. Assessment and Evaluation in Higher Education, 31 (1), 19 - 36 (2006)

4. N. Falchikov. Learning together: Peer tutoring in higher education. London: Routledge Falmer, (2001)

5. F. Tiew. Business student's of peer assessment on class participation. International Education Studies, 3 (3), 126 - 131 (2010)

6. V. Braun, V. Clarke. Using thematic analysis in psychology. Qualitative Research in Psychology , 3 (2), 77 - 101 (2006)

7. J. Mok. A case study of students' perceptions of peer assessment in Hong Kong. ELT Journal, 65(3), 230 -239 (2011)

8. W. Elshami, M. E. Abdalla. Diagnostic radiography students' perceptions of formative peer assessment within a radiographic technique module. Radiography, 23(1), 9 - 13 (2017)

9. C. Domínguez, A. Jaime, A. Sánchez, J. M. Blanco, J. Heras. A comparative analysis of consistency and difference among online self-, peer-, external- and instructor- assessment. Journal Computers in Human Behavior, 60, 112 - 120 (2016)

10. G. Xianwie, M. Samuel, A. Asmawi. A model of critical peer feedback to facilitate business english writing using Qzone weblogs among Chinese undergraduate. Malaysian Online Journal of Educational Technology, 4(4), 1 - 17 (2016)
11. A. Konak, S. Magluilo, S. Kulturel-Konak. Behaviorally anchored rating scales for teamwork peer assessment. 2016 IEEE Integrated STEM Education Conference, 168 - 172 (2016)

12. K. Topping. Self and peer assessment in school and university : Reliability, Validity and Utility, 55 -8 7 (2003)

13. H. Meihami, S. A. Razmjoo. An emic perspective toward challenges and solutions of self- and peerassessment in writing courses. Asian Pacific Journal of Foreign Language Education, 1 - 20 (2016)

14. N. K. L. Pope. The impact of stress in self and peer assessment. Assessment \& Evaluation in Higher Education, 30(1), 51 - 63 (2005)

15. H. Saito, T. Fujita. Charactesristics and user acceptance of peer rating in EFL writing classrooms. Language Testing, 25(4), 553 - 581 (2004)

16. M. Azarnoosh. Peer assessment in an EFL context : attitudes and friendship bias. Language Testing in Asia, 3(11), 1 - 10 (2013)

17. P. Orsmond, S. Merry, K. Reiling. A study in selfassessment :tutor and students' perceptions of performance crateria. Assessment \& Evaluation in Higher Education, 22(4), 357 - 368 (1996)

18. Sabri \& Yunus (2014)

19. Xiao (2010)

20. M. Monga. Intergrity and its antecedent : A unified conceptual freamwork of integrity. Proceeding of the Asia Pacific Conference on Business and Social Sciences 2015, Kuala Lumpur, 171 - 180.

21. A. Barnard. The competencies of integrity. Journal of Psychology in Africa, 21 (2), 267 - 273

22. N.A.B.Z. Abidin, S.B. Sahdan. Peer assessment: A challenge in the new generation. Advanced Science Letters, 23 (3), 908 - 911 (2017)

23. S.B. Sahdan, N.A.B.Z. Abidin. Self-regulated learning: A literature review for 21st century learning technology. Advanced Science Letters, 23 (3), 912 - 915 (2017)

24. R.L. Hulsman, J.F. Peters, M. Fabriek. Peer assessment of medical communication skill: The impact of students' personality, academic and social reputation on behavioural assessment. Patient Education and Counseling, 92, 246 -354 (2013)

25. H. Asikainen, V. Virtanen, L. Postareff, P. Heino. Peer assessment in a large introductory class of gene technology. Studies in Continuing Education, 43, $197-205$ (2014) 